\title{
Informed consent: results of a study in a geriatric surgery division
}

\author{
C Terranova $^{1 *}$, A Bruttocao $^{2}$, R Nistri $^{2}$ \\ From de Senectute: Age and Health Forum \\ Catanzaro, Italy. 5-7 December 2009
}

\section{Background}

Informed consent is a process during which the physician informs the patient of his diagnostic and treatment options; informing the patient about the risks of the procedure as well the benefits, can help him/her to make a rational decision regarding his health. A paternalistic relation between the physician and the patient is antithetical to the concept of informed consent [1]. In elderly patients' impaired decisional capacity, observed in relation to the presence of neurological pathologies like Alzheimer disease and associated disorder [2], can influence the collection of a valid informed decision.

The capacity in elderly patients of a surgery geriatric division was evaluated to discuss the possible implications from an ethical and legal point of view of a correct collection of an informed consent

\section{Patients and methods}

The study is conducted on 100 patients aged over 70 years, hospitalized in a geriatric surgery division during the period September - November 2009. The methodological approach is based on the following steps: 1 . analysis of medical documentation; 2. anamnesis; 3. collection of data concerning education, previous informed consent, knowledge of diagnostic and treatment options; 4 . clinical-behavioral examination by means of administration of Mini-mental state examination (MMSE) and clock drawing test. The collected data are recorded in a database.

\section{Results}

Preliminary results in some cases highlight impaired cognitive functions that could influence the expression of a valid informed consent.

\section{Conclusions}

Informed consent is relevant from an ethical and legal point of view. The analysis of the data highlights the importance of the physician - patient relationship in the collection of the informed consent. In some cases the physician should be aware of the possibility of identifying the patient's characteristics associated with impaired capacity; in such cases formal capacity evaluations and/ or enhanced consent procedures may be most appropriate.

\section{Author details}

${ }^{1}$ Department of Environmental Medicine and Public Health, University of Padua, Italy. ${ }^{2}$ Department of Surgical and Gastroenterological Sciences, University of Padua, Italy.

Published: 19 May 2010

\section{References}

1. Humayun A, Fatima N, Naqqash S, Hussain S, Rasheed A, Imtiaz H, Imam SZ: Patients' perception and actual practice of informed consent, privacy and confidentiality in general medical outpatient departments of two tertiary care hospitals of Lahore. BMC Medical Ethics 2008, 9:14.

2. Karlawish JH, Casarett DJ, James BD: Alzheimer's disease patients' and caregivers' capacity, competency, and reasons to enroll in an earlyphase Alzheimer's disease clinical trial. J Am Geriatr Soc 2002, 50:2019-2024.

\section{doi:10.1186/1471-2318-10-S1-A36}

Cite this article as: Terranova et al.: Informed consent: results of a study in a geriatric surgery division. BMC Geriatrics 2010 10(Suppl 1):A36. 